\title{
Lymphoma in Remission
}

National Cancer Institute

\section{Source}

National Cancer Institute. Lymphoma in Remission. NCI Thesaurus. Code C158581.

History of lymphoma with no evidence of disease after therapy. 